\title{
PATTERNS OF DRUG UTILIZATION IN CARDIOLOGY DEPARTMENT OF A TERTIARY LEVEL HOSPITAL IN BANGLADESH
}

\author{
FARHANA AFROJ ${ }^{1}$, FEROZA PARVEEN ${ }^{2}$, FERDOUS ARA ${ }^{3}$, MD JALAL UDDIN IQBAL ${ }^{4}$, REKHA RANI SAHA ${ }^{5}$, RINI JULIET \\ ROZARIO ${ }^{6}$
}

${ }^{1}$ Assistant Professor, Department of Pharmacology, Shaheed Monsur Ali Medical College, Dhaka

${ }^{2}$ Professor, Department of Pharmacology, Green Life Medical College, Dhaka

${ }^{3}$ Professor, Department of Pharmacology, Sir Salimullah Medical College, Dhaka

${ }^{4}$ Associate Professor, Department of Pharmacology, Sir Salimullah Medical College, Dhaka

${ }^{5}$ Associate Professor, Department of Pharmacology, Sir Salimullah Medical College, Dhaka

${ }^{6}$ Associate Professor, Department of Pharmacology, Shaheed Monsur Ali Medical College, Dhaka

\begin{abstract}
A cross-sectional descriptive study was carried out among patients admitted in cardiology department from $1^{\text {st }}$ January to $31^{\text {st }}$ March 2011 in Sir Salimullah Medical College \& Mitford Hospital, Dhaka to see the patterns of prescriptions and use of drug by using WHO core drug use indicators and some additional indices. A total of 300 patients were included in this study. The average number of drugs per encounter was 8.8 and $11.43 \%$ drugs were prescribed by generic name. Percentage of encounters with cardiovascular drugs were 64\%,other drugs were $36 \%$ and $25 \%$ injection were prescribed.70.45\% drugs were prescribed from EDL of Bangladesh, the availability of copy of essential drug list was present and availability of key drugs was $74 \%$.So the results of the present study may contribute to identify essential drug prescribing patterns in our country.
\end{abstract}

Keywords: Patterns of drug utilization, essential drug, cardiovascular system, generic name.

(Bangladesh J Physiol Pharmacol 2012;28(1\&2):1-4.)

\section{INTRODUCTION}

By enhancing the standards of medical treatment at all levels of the healthcare delivery system the quality of life in developing countries can be improved. ${ }^{1}$ Drug utilization research has been defined by the WHO as "the marketing, distribution, prescription \& use of drugs in a society, medical, social \& economic consequences". ${ }^{2}$ The assessment of drug utilization is important for - clinical, education, economic purposes. ${ }^{3}$

Prescribing patterns need to be evaluated periodically to - increase the therapeutic efficacy, decrease adverse effects, provide feedback to prescribers. ${ }^{4-5}$ Drug utilization reviews are useful for obtaining information about drug use patterns and for identifying high cost drugs. ${ }^{6}$ To assess the scope for improvement in rational drug use in patient practice, the WHO in 1993 has formulated a set of 'core drug use indicators'.

\section{THE INDICATORS ARE}

Prescribing indicators, patient care indicators, facility indicators.

Address for correspondence: Dr. Farhana Afroj, Assistant Professor, Department of pharmacology, Shaheed Monsur Ali Medical College, Uttara, Dhaka. Mobile No: 01710859058 E-mail: Farhanaafroj@yahoo.Com
Since the 1970s WHO has promoted equitable access to basic health services through the concepts of primary health care and essential drugs. The first Model list of essential drugs of 1977 preceded the famous 1978 Alma Ata Declaration on Health for all and is widely regarded as one of WHO's most influential public health achievements. ${ }^{8}$ Lately the term 'drugs' has been replaced by 'medicines' since $2001 .{ }^{9}$ Therefore, in many countries even the developed nations have applied the essential drugs list in order to improve care and manage drugs costs as the list serves to maintain drug affordability amongst a selection of essential drugs. ${ }^{10}$ The causes of access gap to essential drugs and the measures which are needed to close the gap is linked to a set of fundamental economic, social and educational factors that lie beyond the health sector system. ${ }^{11}$ High costs of medicines results in poor access to the public even in rich countries. ${ }^{12}$ Moreover, the WHO has reported that many people throughout the world cannot obtain the drugs they need due to its unaffordability. ${ }^{13}$ Cardiovascular diseases are one of the major health problems in Bangladesh \& other developing countries. National data on incidence \& mortality of coronary heart disease are few in Bangladesh. Though, a number of investigations on these aspects have been undertaken 
in different countries, but still no such data has yet been published or has never been seriously looked into in our country. Therefore, the present study has been undertaken to observe the essential drug prescribing patterns among the admitted patient in the cardiology department in a tertiary level hospital in Bangladesh.

\section{MATERIAL \& METHODS}

A cross sectional descriptive study was carried out in the Cardiology department of Sir Salimullah Medical College \& Mitford Hospital, Dhaka, which is a 600 bed tertiary hospital that serves as a major teaching hospital in Bangladesh. All the patients (male \& female) who were admitted in CCU during study period were considered for analysis. Patients who visited the cardiac unit for follow-up, patients transferred to another department and who expired were excluded from the study. The sample size was 300 . The required information was collected from the treatment records of the patients admitted in cardiology department of the hospital. Treatment records were used for data analysis. The information in the treatment records was used to complete customized proforma. The age of the patients, gender, particulars of the patients, diagnosis, co-morbid conditions were noted. The average number of drugs per prescription, most commonly prescribed cardiovascular drugs, percentage of drugs prescribed by generic names, percentage of drugs prescribed from Essential Drug List (EDL) of Bangladesh, percentage of encounters with an injection prescribed and other drugs. The data was expressed as percentage, mean and total numbers.

\section{RESULTS}

A total of 300 prescriptions were analyzed during the study period. Among the 300 patients, 187 patients (62\%) were male and 113 patients (38\%) were female, the age group between $51-60$ years accounted for the highest number [ $85(28.33 \%)]$, most of the patients (55\%) came from middle income group and $44 \%$ from low income group. The total number of drugs amongst 300 prescriptions were 2640 and the average drugs per prescription was 8.8 , the range of drugs per encounter varied from 3-10. Ten (10) drugs were prescribed in 162 prescriptions (54\%) was found to be highest, out of 300 prescriptions, myocardial infarction with hypertension $[160(53 \%)]$ was the most common diagnosis, the oral dosage form accounted for $74 \%$ of drugs which was prescribed most commonly. Injection use was high. A total of $25 \%$ injections and $1 \%$ inhalational drugs were prescribed. Most of the drugs were not prescribed by generic names. Only 302 drugs $11.43 \%$ were prescribed by generic names. It was seen that out of 300 prescriptions the majority of the drugs $1860(70 \%)$ were prescribed from the Essential Drug list (EDL) of Bangladesh and only 680 drugs (30\%) were other than EDL of Bangladesh. The most commonly prescribed cardiovascular drug was tab aspirin and clopidogrel 278 (93\%) followed by tab atorvastatin, ramipril, amlodipine, frusemide, glyceryltrinitrate, digoxin, Inj heparin, streptokinase, amiodarone. The commonest co-morbid condition seen in these groups of patients was diabetes mellitus seen in $13.66 \%$ of the patients closely followed by chronic obstructive pulmonary disease, stroke, bronchial asthma, hypothyroidism, chronic kidney disease.

The overall findings for the WHO core drug use indicators are listed in Table 1:

Table 1

Pattern of WHO core drug use indicators in medical admitted patients.

\begin{tabular}{|c|c|}
\hline WHO core drug use indicator & Findings \\
\hline $\begin{array}{ll}\text { - } & \text { Prescribing indicators } \\
\text { - } & \text { Average number of drugs per prescription. } \\
\text { name. } & \text { Percentage of encounters with an injection } \\
\text { - } & \text { prescribed. } \\
\text { - } & \text { Percentage of drugs prescribed from essential } \\
\text { drug list of Bangladesh. } \\
\text { Facility indicators } \\
\text { - Availability of copy of essential drug list } \\
\text { - Availability of key drugs } \\
\text { - Some additional indices } \\
\text { Percentage of encounters with cardiovascular } \\
\text { drugs }\end{array}$ & $\begin{array}{c}8.8 \\
11.43 \\
25 \\
70.45 \\
\text { Present } \\
74 \% \\
64 \\
36\end{array}$ \\
\hline
\end{tabular}

\section{DISCUSSION}

Cardiovascular diseases are leading causes of morbidity and mortality in the industrialized countries and also emerging as a prominent public health problem in the developing countries. High rates of coronary heart disease in people of South Asian origin were first 
reported from Singapur, South Africa \& Trinidad in the 1950s; similar findings were recorded in the United Kingdom at the time of the 1971 census. ${ }^{14}$ The present study has been undertaken to see the patterns of essential drug utilization among the admitted patient in the cardiology department in a tertiary level hospital in Bangladesh. Recently, there has been a rigorous effort to ensure RUD for which WHO has identified specific drug use indicators that include number and cost of drugs, use of generic names in prescribed drugs and adherence to Essential Drug List (EDL). ${ }^{15}$ Gender analysis showed higher number of male patients $[187\{62 \%\}]$ than female $[113\{38 \%\}$. As mentioned by previous researcher in Malaysia, the frequency of prescriptions for cardiovascular drugs for men was higher than that for women. ${ }^{16}$ The age distribution of the patients showed that patients $(51-60)$ constituted the highest number (28.33\%) admitted in Hospital which was comparable with the results in Malaysia. ${ }^{16}$ In the present study, total $99 \%$ of patients were admitted in the Hospital from the low and middle income groups. The findings could be attributed to poverty which is a major risk factor for poor health outcomes. As it was observed that, $62 \%$ male patients seen in this study, majority of them were businessman (38\%). Since this hospital is located in the commercial area so numbers of businessman were found to be highest and the percentage of female patients $(31 \%)$ were found the second highest and most of them were housewives. The average number of drugs per prescription in this study was 8.8 which is comparable with the study done by Decan College of Medical sciences, Hyderabad, India $2010(9.93)^{17}$ and UKM Hospital, Malaysia 2007 (7.56)..$^{16}$ However studies done by Kasturba Medical College, Mangalore, India2010 (4.53) ${ }^{18}$ and Manipal Teaching Hospital, Nepal 2002 (3.39) shows incomparable with this study. ${ }^{19}$ Out of 300 prescriptions, myocardial infarction with hypertension (53\%) was the most common diagnosis followed by acute coronary syndrome $19 \%$, heart failure $10 \%$, ischemic cardiomyopathy $6 \%$, valvular and rheumatic heart disease $5 \%$, angina pectoris $3 \%$ and this diagnosis was collected from the treatment records in the Mitford Hospital. In our study, high prescribing frequency of the antiplatelets $93 \%$, lipid lowering agent $86 \%$, antihypertensive $71 \%$, diuretics $40 \%$, glyceryltrinitrate $42 \%$, anticoagulants $33 \%$, and thrombolytic agent $20 \%$. The commonest co morbid condition was Diabetes mellitus seen in $13.66 \%$ of the patients. The percentage of drugs prescribed by generic name was $11.43 \%$ in this study which were comparable with Hyderabad, India $6 \%{ }^{17}$ In Malaysia $45.2 \%$ and Nigeria $37.4 \%$ which were not comparable. ${ }^{16,20} 74 \%$ drugs were prescribed in oral dosage form and the percentage of prescription with an injection was $25 \%$. The recommended target for injection exposure is $10 \%$ or less. ${ }^{7}$ In the present study, it was $25 \%$ injection per prescription which were comparable with China (2011) $22.63 \% .^{21}$ In this study, the percentage of drugs prescribed from essential drugs list of Bangladesh was $70 \%$. The possible reason for this higher value could be the prescriber's knowledge, understanding and importance of essential drug concept. The availability of key drugs was $74 \%$ as the most of the drugs were available in medicine store of the hospital. To measure the practical implementation of National Drug Policy, measurement of percentage of drug from EDL or formulary was observed. The proper selection of essential drug, useful for dealing with the majority of health problem cuts down the number of unnecessary product to be manufactured, promoted and marketed. This makes the health professionals and patients to be familiar with the essential drug easily.

\section{CONCLUSION}

Further studies from time to time are required in drug utilization pattern and standard treatment guidelines to be circulated among the practicing physicians to improve the quality of life.

\section{ACKNOWLEDGEMENT}

The authors would like to express their gratitude to the Health Board of the Belo Maternity, the ethical committee for the administrative and ethical clearances and all the gestation mothers who accepted to participate in this study.

\section{REFERENCES}

1. Patterson HR: The problems of audit and research. J R coll Gen pract, 1986. 36; 196.

2. World Health Organization (WHO). Introduction to drug utilization research. Oslo: 2003

3. Uppal R, Nayak P, Sharma PL. Prescribing trends in internal medicine. Int J Clin Pharm Ther Toxicol 1984; 22: 373-376.

4. Krishnaswamy K, Dinesh Kumar B, Radhaiah G. A drug use surveyprecepts and practices. Eur J Clin Pharmacol 1985; 29: 363-370.

5. Islam MS, Rahman MS, Misbahuddin M. Impact of 'Prescription Audit \& Feedback' on Pattern of Prophylactic Antimicrobials in Caesarean Section: a Cost Reduction Perspective. Bang J Physiol Pharmacol 2007; 23: 1-9.

6. Marshner JP, Thurmann P, Harder S, Rietbrock N. Drug utilization review on a surgical intensive care unit. Int J Clin Pharmacol Ther 1994; 32: 447-451.

7. World Health Organization. How to investigate drug use in health facilities: Selected drug use indicators 1993. EDM Research Series No. 7 [WHO/DAP/93.1].

8. Hogerzeil HV. Essential medicines and human rights: what can they learn from each other? Bull World Health Org 2006; 84: 371375.

9. Trouiller P. World Health Organization Essential Drug List Encyclopedia of Clinical Pharmacy 2002.

10. Reidenberg MM, Walley $\mathrm{T}$. The pros and cons of essential medicines for rich countries. BMJ 2004; 329: 1172.

11. Quick JD. Essential medicines twenty-five years on: closing the access gap. Health Pol Plan 2003; 18: 1-3. 
12. Lopert R, Lang DL, Hill SR, Henry DA. Differential pricing of drugs: a role for cost-effectiveness analysis? Lancet 2002; 359:21052107.

13. World Health Organization (WHO). How to develop and implement a national drug policy. $2^{\text {nd }}$ ed. Geneva: WHO; 2001.

14. The Daily Star (Internet Edition) Saturday. June 21, 2003. (URL:http://www.thedailystar.net/2003/06/21/d3062101022.htm).

15. Enwere OO, Falade CO, Salako BL. Drug prescribing pattern at the medical outpatient clinic of a tertiary hospital in southwestern Nigeria. Pharmacoepidemiol Drug Saf 2007; 16: 1244-1249.

16. I-Junid SM, Ezat WPS, Surianti S. Prescribing Patterns and Drug Cost Among Cardiovascular Patients in Hospital University Keban Saan Malaysia. Med. J. Malaysia, 2007; Vol.62, No.1.

17. Sandozi $T$, Nausheen F. Drug utilization study in Ischemic heart Diseases Associated with Diabetes and Hypertension. Int J Pharma Bio Sci 2010: 1(3).
18. Rathnakar UP et al. Profile of Drug Utilization Among Elderly Patients Attending a Cardiology Clinic In Mangalore, India. J Pharmacy Res 2010; 3(8), 1835-1837.

19. Shankar RP, Patha P. Shenoy N. Prescribing patterns of Drugs among Patients admitted with Cardiovascular Disorders in the internal Medicine ward: prescribing patterns in inpatients. Internet J Pharmacol 2002; 1(2).

20. Nwidu LL, Essien GE, N-Chris EE. Pattern of Prescription in cardiovascular diseases management in Port Harcourt City. Nigeria J Pharm Res 2009; 2: 1653-1658.

21. Jun Z, Linyun Li, Che Z, Vuanrong Y, Fengzi G, Heng Z, Analysis of outpatient prescription indicators and trends in Chinese Jingzhou Area between Sep.1 and 10, 2006-2009. Afr J Pharm Pharmacol 2011; 5: 270-275. 